\title{
The role of microRNA deregulation in the pathogenesis of adrenocortical carcinoma
}

\author{
Deniz M Özata ${ }^{1,2 *}$, Stefano Caramuta ${ }^{1,2 *}$, David Velázquez-Fernández ${ }^{1,2}$, \\ Pinar Akçakaya ${ }^{1,2}$, Hong Xie ${ }^{1,2}$, Anders Höög ${ }^{3}$, Jan Zedenius ${ }^{1,4}$, \\ Martin Bäckdahl, ${ }^{1,4}$, Catharina Larsson ${ }^{1,2}$ and Weng-Onn Lui ${ }^{1,2}$
}

\author{
${ }^{1}$ Department of Molecular Medicine and Surgery, Karolinska Institutet, SE-17176 Stockholm, Sweden \\ ${ }^{2}$ Center for Molecular Medicine and ${ }^{3}$ Department of Oncology-Pathology, Karolinska University Hospital Solna, SE-17176 \\ Stockholm, Sweden \\ ${ }^{4}$ Department of Breast and Endocrine Surgery, Karolinska University Hospital, SE-17176 Stockholm, Sweden \\ (Correspondence should be addressed to S Caramuta at CMM L8:01, Karolinska University Hospital-Solna, SE-17176 Stockholm, \\ Sweden; Email: stefano.caramuta @ki.se; W-O Lui at Department of Molecular Medicine and Surgery, Karolinska Institutet; \\ Email: weng-onn.lui@ki.se) \\ *(D M Özata and S Caramuta contributed equally to this work)
}

\begin{abstract}
Adrenocortical carcinoma (ACC) is an aggressive tumor showing frequent metastatic spread and poor survival. Although recent genome-wide studies of ACC have contributed to our understanding of the disease, major challenges remain for both diagnostic and prognostic assessments. The aim of this study was to identify specific microRNAs (miRNAs) associated with malignancy and survival of ACC patients. miRNA expression profiles were determined in a series of ACC, adenoma, and normal cortices using microarray. A subset of miRNAs showed distinct expression patterns in the ACC compared with adrenal cortices and adenomas. Among others, miR-483-3p, miR-483-5p, $m i R-210$, and $m i R-21$ were found overexpressed, while $m i R-195, m i R-497$, and $m i R-1974$ were underexpressed in ACC. Inhibition of $m i R-483-3 p$ or $m i R-483-5 p$ and overexpression of $m i R-195$ or miR-497 reduced cell proliferation in human $\mathrm{NCl}-\mathrm{H} 295 \mathrm{R}$ ACC cells. In addition, downregulation of $m i R-483-3 p$, but not $m i R-483-5 p$, and increased expression of miR-195 or miR-497 led to significant induction of cell death. Protein expression of p53 upregulated modulator of apoptosis (PUMA), a potential target of miR-483-3p, was significantly decreased in ACC, and inversely correlated with $m i R-483-3 p$ expression. In addition, high expression of $m i R-503, m i R-1202$, and miR-1275 were found significantly associated with shorter overall survival among patients with ACC ( $P$ values: $0.006,0.005$, and 0.042 respectively). In summary, we identified additional miRNAs associated with ACC, elucidated the functional role of four miRNAs in the pathogenesis of ACC cells, demonstrated the potential involvement of the pro-apoptotic factor PUMA (a miR-483-3p target) in adrenocortical tumors, and found novel miRNAs associated with survival in ACC.
\end{abstract}

Endocrine-Related Cancer (2011) 18 643-655

\section{Introduction}

Patients with tumors of the adrenal cortex may present an incidentally detected or hormonally overproducing adrenocortical adenoma, or uncommonly an adrenocortical carcinoma (ACC). ACC is an aggressive tumor associated with poor prognosis in adults (Bertherat et al. 2006). Differential diagnosis between ACC and the more common adenoma is difficult, particularly for the tumors in the marginal category, i.e. Weiss score 2 or 3 vs 4 . Moreover, prognostic tools for early recognition of metastatic ACC disease and adverse outcome are presently lacking in routine diagnostics. Profilings of mRNA and microRNA (miRNA) expressions in human cancer have revealed important alterations that do not only have possible diagnostic and prognostic value but also point toward molecular alterations of mechanistic importance for tumor etiology and progression.

In adrenocortical tumors, mRNA expression profilings by several independent groups have revealed significant and reproducible alterations for the 
discrimination of adenoma and ACC and for the determination of ACC prognosis (Giordano et al. 2003, de Fraipont et al. 2005, Velazquez-Fernandez et al. 2005, Giordano et al. 2009, Laurell et al. 2009, de Reynies et al. 2009, Soon et al. 2009a). One of the most striking finding was the significant overexpression of insulin-like growth factor 2 (IGF2) in ACC, which was observed in $>80 \%$ of cases compared with adrenal cortices and hormonally active/inactive adenomas (Giordano et al. 2009, Laurell et al. 2009, de Reynies et al. 2009). In addition, the expression levels of other genes such as DLG1 and PINK1 have been associated with the clinical outcome of ACC (de Reynies et al. 2009).

miRNAs are $\sim 22$ nucleotide long single-stranded non-coding RNAs generated by the RNase-III enzyme Dicer from endogenous hairpin-shaped transcripts (Iorio \& Croce 2009). miRNAs have diverse roles in many biological processes and have also been shown important for tumor development, by acting as oncogenic or tumor suppressive species. Besides, accumulating evidence also supports a role of miRNAs as diagnostic and prognostic biomarkers of human cancers (Iorio \& Croce 2009, Ferracin et al. 2010). Profilings of adrenocortical tumors have identified several deregulated miRNAs in benign adrenocortical diseases (Iliopoulos et al. 2009, Bimpaki et al. 2010), as well as ACC (Soon et al. 2009b, Tombol et al. 2009, Doghman et al. 2010, Patterson et al. 2011). Several deregulated miRNAs have been reported in ACC, including overexpression of $m i R-483-3 p$ and $m i R-483-5 p$, which are transcribed from an intronic sequence of the IGF2 gene (Soon et al. 2009b, Doghman et al. 2010). $m i R-483-3 p$ has recently been shown to target the pro-apoptotic gene BCL-2-binding component 3/p53 upregulated modulator of apoptosis (BBC3/PUMA) in cancers of the colon, liver, and breast (Veronese et al. 2010), suggesting its anti-apoptotic role in a variety of tumor types.

In this study, we characterized miRNA expression patterns of ACC compared with adenomas and normal adrenal cortices, and related the findings to outcome at follow-up. The functional consequences of $m i R-483-3 p, m i R-483-5 p, m i R-195$, and $m i R-497$ deregulations were studied in vitro concerning cell proliferation and apoptosis. We further explored the involvement of PUMA, a potential target of $m i R-483-3 p$, in clinical samples. Our findings may contribute to further understanding of ACC development, and suggest a role for selected miRNAs as diagnostic and prognostic biomarkers in ACC.

\section{Materials and methods}

\section{Tumors and normal tissues}

A total of 68 snap-frozen primary sporadic adrenocortical tumors collected at the Karolinska University Hospital were included in this study. In addition, histopathologically verified normal adrenal cortical samples were obtained from ten patients undergoing nephrectomy for other reasons and used as nonneoplastic reference tissues. All samples were obtained with informed consent and the study of the tissue materials was approved by the Local Ethics Committee. Tumors were diagnosed following the WHO classification (DeLellis et al. 2004) as adrenocortical adenoma (Ad 1-43) or ACC (Ca 1-25). Clinical details have been partly published for subsets of the cases in previous studies (Laurell et al. 2009). All 25 carcinoma cases were followed-up until May 2011 or until their death, and the follow-up data is detailed together with clinical and histopathological information in Supplementary Table 1, see section on supplementary data given at the end of this article. Thirteen of the 43 adenoma cases were cortisol-producing tumors (Cushing) from one male and 12 female patients with a mean age of diagnosis at 56 years (range 27-81) and a mean tumor size of $3.8 \mathrm{~cm}$ (range 1.5-6.5). Sixteen adenomas were aldosteronomas (five male and 11 female patients) with a mean age of 46 years (range 16-79) and a mean tumor size of $2.0 \mathrm{~cm}$ (range $0.9-4.7$ ). The last 14 adenomas were classified as incidentalomas (six male and eight female patients) with a mean age of 59 years (range 42-65) and a mean size of $3.9 \mathrm{~cm}$ (range 2.5-5.3). The median follow-up time for adenomas was 39 months (range 12-258). At the end of the follow-up, no adenoma patient had disease progression or metastasis.

\section{Cell line}

The ACC cell line NCI-H295R was purchased from the American Type Culture Collection (ATCC\# CRL-2128; LGC Standards, Middlesex, UK). Cells were maintained in DMEM:F12 medium containing $2.5 \%$ of NuSerum (cat. no. 355500; BD Biosciences, Bedford, MA, USA), $1 \%$ penicillin/streptomycin and $1 \%$ insulin-transferin-sodium selenite (ITS +1 ) liquid media supplement (cat. no. I2521; Sigma-Aldrich Logistik $\mathrm{GmbH}$ ) at $37{ }^{\circ} \mathrm{C}$ and $5 \% \mathrm{CO}_{2}$. Authentication of the cell line was evaluated and verified by BioSynthesis, Inc. (Lewisville, TX, USA) employing genotyping of 15 short tandem repeat (STR) loci and the amelogenin gene (AMEL), and comparison with genotype information at the ATCC (Supplementary Table 2 , see section on supplementary data given at the end of this article). 


\section{RNA extraction}

Total RNA isolation was performed by mirVana miRNA Isolation Kit (Applied Biosystems/Ambion, Austin, TX, USA). Measurement of RNA concentrations was done using a NanoDrop ND-1000 spectrophotometer (NanoDrop Technologies, Wilmington, DE, USA).

\section{Microarray-based miRNA profiling}

Global miRNA expression profiling of adrenocortical tumors and normal cortices was performed by the Human Agilent's miRNA microarray system (Agilent, Santa Clara, CA, USA) with probes matching 903 human miRNAs (miRBase release 14). Array hybridizations and data analyses were performed essentially as described previously (Caramuta et al. 2010). In brief, samples of $120 \mathrm{ng}$ total RNA were labeled with Cyanine 3-pCp, hybridized onto arrays for $18-20 \mathrm{~h}$ at $55^{\circ} \mathrm{C}$, followed by washing. Slides were scanned in an Agilent microarray scanner G2565BA and images were processed with Feature Extraction Software v10.7.3.1 (Agilent). Cluster 3.0 Software (http://bonsai.hgc.jp/ mdehoon/software/ cluster/) was used for normalization and median centering (de Hoon et al. 2004). Normalized miRNAs with $<50 \%$ missing values were included in subsequent analyses for hierarchical clustering and significance analysis of microarrays (SAM). The data from microarray analysis have been deposited at NCBI Gene Expression Omnibus (GEO accession number, GSE22816).

\section{QRT-PCR analysis of individual miRNAs}

Selected mature miRNAs were quantified using commercially available TaqMan qRT-PCR assays (Applied Biosystems) and a 7900HT Real-Time PCR System (Applied Biosystems). cDNA was synthesized from $25 \mathrm{ng}$ total RNA using TaqMan mRNA RT Kit (Applied Biosystems) and used for quantification of $m i R-483-3 p$ (ID 002339), $m i R-483-5 p$ (ID 002338), miR-497 (ID 001043), miR-195 (ID 000494), miR-1974 (ID 121209_mat), miR-210 (ID 000512), $m i R-21$ (ID 000397), miR-503 (ID 001048), $m i R-1202$ (ID 002858), miR-1275 (ID 002840), $m i R-638$ (ID 001582), miR-1915 (ID 121111_mat), and $m i R-572$ (ID 001614) with normalization against $R N U 6 B$ (ID 001093). All reactions were performed in triplicate, and relative expression levels were determined with the $\Delta C_{\mathrm{T}}$ method and reported as $2^{-\Delta \mathrm{C}_{\mathrm{T}}}$.

\section{miRNA inhibition and overexpression in $\mathrm{NCl}-\mathrm{H} 295 \mathrm{R}$ cells}

NCI-H295R ACC cells were transfected using Nucleofector Technology (Amaxa Biosystems, Gaithersburg, MD, USA). In brief, $3 \times 10^{6}$ cells were resuspended in $100 \mu \mathrm{l}$ Nucleofector solution R, and mixed with 100 pmol of miRNA inhibitors (anti-miR483-3p or anti-miR-483-5p; Applied Biosystems/ Ambion) or miRNA precursors (pre-miR-195 or pre-miR-497; Applied Biosystems/Ambion). AntimiR-negative control \#1 or pre-miR-negative control \#1 (Applied Biosystems/Ambion) containing a nontargeting sequence molecule was used as a negative control. Cells were then electroporated using the program T-20, allowed to recover in DMEM:F12 media for $15 \mathrm{~min}$ at $37^{\circ} \mathrm{C}$ and seeded in T-25 flasks with $5 \mathrm{ml}$ DMEM:F12 media. Culture media was replaced after $24 \mathrm{~h}$ and cells were cultured for additional $72 \mathrm{~h}$. All transfection experiments were repeated at least three times and used for proliferation and apoptosis assays. Transfection efficiency was determined by measuring the endogenous $m i R-483-3 p$, $m i R-483-5 p$, miR-195, or $m i R-497$ expression levels by qRT-PCR (Supplementary Figure 1, see section on supplementary data given at the end of this article). To demonstrate that the transfected miRNAs achieved physiologically relevant expression levels, we compared the expression fold change differences between the experimental cell culture systems (anti-miRNA/ pre-miR versus control) and the clinical materials (carcinomas versus normal cortices) for $m i R-483-3 p$, miR-483-5p, miR-195, and miR-497. In the transfected cells expressing specific miRNA assayed, we observed a reduction of $\sim 12$-fold for $m i R-483-3 p$ and approximately ninefold for miR-483-5p while we noticed $\sim 15$ - and 30-fold increase for miR-195 and miR-497, respectively, compared with the negative control. The effect of transfections had a similar magnitude of miRNA expression levels as for the comparison between carcinomas and normal adrenal cortices. In carcinomas, we observed an average increased expression of 166-fold (range 0.1-1330) and 73-fold (range $0.1-400$ ) for $m i R-483-3 p$ and $m i R-483-5 p$, respectively; but a reduced expression of sixfold (range 0.6-26) and 18-fold (range 0.3-170) for $m i R-195$ and $m i R-497$ respectively.

\section{Cell proliferation WST-1 colorimetric assay}

WST-1 (4-(3-(4-iodophenyl)-2-(4-nitrophenyl)2H-5-tetrazolio)-1,3-benzene disulfonate; cat. no. 11644807001; Roche Applied Science) colorimetric assay was carried out to determine the effects of 
$m i R-483-3 p$ and $m i R-483-5 p$ inhibition or $m i R-195$ and miR-497 overexpression on cell proliferation. The assay was performed by 96 -well plates, with seeding of $\sim 20000$ cells in each well. After $72 \mathrm{~h}$ of transfection, $20 \mu$ of the WST- 1 solution were added to the culture medium and incubated for $2.5 \mathrm{~h}$ at $37^{\circ} \mathrm{C}$. Absorbance was subsequently determined using a microplate ELISA reader (VERSAmax; Molecular Devices, Sunnyvale, CA, USA) and analyzed with SoftMax Pro 5 Software (Molecular Devices) applying the wavelengths $450 \mathrm{~nm}$ for measurements and $650 \mathrm{~nm}$ as reference. All experiments were conducted in eight wells for each condition, and replicated at least three times. Cell proliferation was calculated by comparing the absorbance values of the samples after background subtraction. The fraction of surviving cells was calculated by defining the anti-miR- (or pre-miR)negative control \#1-treated cells as one.

\section{Apoptosis caspase- 3 colorimetric assay}

The caspase-3 colorimetric assay (cat. no. L00289; Genscript, Piscataway, NJ, USA) was used to evaluate the effects of $m i R-483-3 p$ and $m i R-483-5 p$ inhibition or $m i R-195$ and $m i R-497$ overexpression on apoptosis; $3 \times 10^{6}$ cells were transfected and seeded in T-25 flasks. After $72 \mathrm{~h}$ of transfection, proteins were isolated and quantified by Bio-Rad Protein Assay (Bio-Rad). Fifty microliters of lysate containing $50 \mu \mathrm{g}$ protein was mixed with $50 \mu \mathrm{l}$ of $2 \times$ reaction buffer and $5 \mu \mathrm{l}$ of caspase- 3 substrate and incubated for $4 \mathrm{~h}$ at $37^{\circ} \mathrm{C}$. Absorbance was subsequently determined using a microplate ELISA reader (VERSAmax; Molecular Devices) and analyzed with SoftMax Pro 5 Software (Molecular Devices) applying the wavelengths $405 \mathrm{~nm}$ for measurement. Apoptosis was calculated by comparing the absorbance values of the anti-miR/pre-miR treated cells with the respective negative control-treated cells. All the experiments were replicated three times.

\section{Western blot analysis}

Whole cell lysates were prepared from normal and tumor tissue samples by homogenization in NP-40 lysis buffer (cat. no. FNN0021; Invitrogen), with addition of protease inhibitor (complete protease inhibitor cocktail; Roche Diagnostics Corporation) and $1 \mathrm{mM}$ of phenylmethanesulfonyl fluoride (Sigma-Aldrich). After quantification by Bio-Rad Protein Assay (Bio-Rad), $60 \mu \mathrm{g}$ of lysate was separated in Novex $10 \%$ Tricine gels (Invitrogen) and transferred to nitrocellulose membranes (LC2001; Invitrogen). Filters were blocked with 5\% non-fat milk diluted in TBS $/ 0.05 \%$ Tween 20 , and incubated with rabbit polyclonal anti-PUMA antibody (\#4976, Cell Signaling Technology, Danvers, MA, USA) at 1:1000 dilution, followed by an antirabbit IgG-HRP (1:3000; \#170-6515; Bio-Rad Laboratories) used as secondary antibody. Detection was carried out with Novex ECL HRP chemiluminescent substrate reagent (\#WP20005; Invitrogen). Novex Sharp Pre-stained protein standards (\#57318; Invitrogen) and MagicMark XP (\#LC5602; Invitrogen) markers were used to determine relative molecular weights. Protein levels were quantified on X-ray films from immunoblots using ImageJ Software (http://rsb. info.nih.gov/ij/). Subsequent incubation of the filters with an anti-GAPDH antibody (sc-47724; Santa Cruz Biotechnology, Inc, Santa Cruz, CA, USA) diluted at 1:5000 was performed for normalization purposes.

\section{Statistical analysis}

All analyses were performed by Statistica 8.0 (StatSoft, Inc., Tulsa, OK, USA) or MS Office Excel 2007, unless otherwise specified. Unpaired Student's $t$-test was conducted to compare miRNA expressions in different groups, while paired Student's $t$-test was performed to analyze transfection experiments. Correlations between $m i R-195$ and $m i R-497$, and $m i R-483-3 p$ and PUMA expression levels were assessed by Pearson's correlation analyses and $P$ values were estimated by permuting the samples. SAM survival analysis was used to identify miRNAs associated with survival. $P$ values were obtained for the Cox score statistics using the $\chi^{2}$-distribution. For survival analysis, all patients who died of unknown causes or causes unrelated to ACC (i.e. $\mathrm{Ca} \mathrm{3,} \mathrm{Ca} 7, \mathrm{Ca} \mathrm{12,} \mathrm{and} \mathrm{Ca}$ 14) during follow-up were considered as 'censored'. Selected miRNAs potentially associated with survival were analyzed by TaqMan qRT-PCR and carcinoma patients were classified into different groups with high or low expression of each miRNA according to median level. The interrelationship of miRNAs with survival was studied using Kaplan-Meier plots, and the curves for each group were compared by log-rank test. All the analyses were twotailed and $P$ values $<0.05$ were considered significant.

\section{Results}

\section{Deregulated miRNAs in ACC}

In this study, we characterized miRNA expression patterns in a cohort of 48 adrenocortical tumors (26 adenomas and 22 carcinomas) and four normal adrenal cortices using a microarray-based approach. Unsupervised clustering analysis classified the samples in different subgroups based on the similarity of their miRNA expression profiles. In Fig. 1, clustering based 


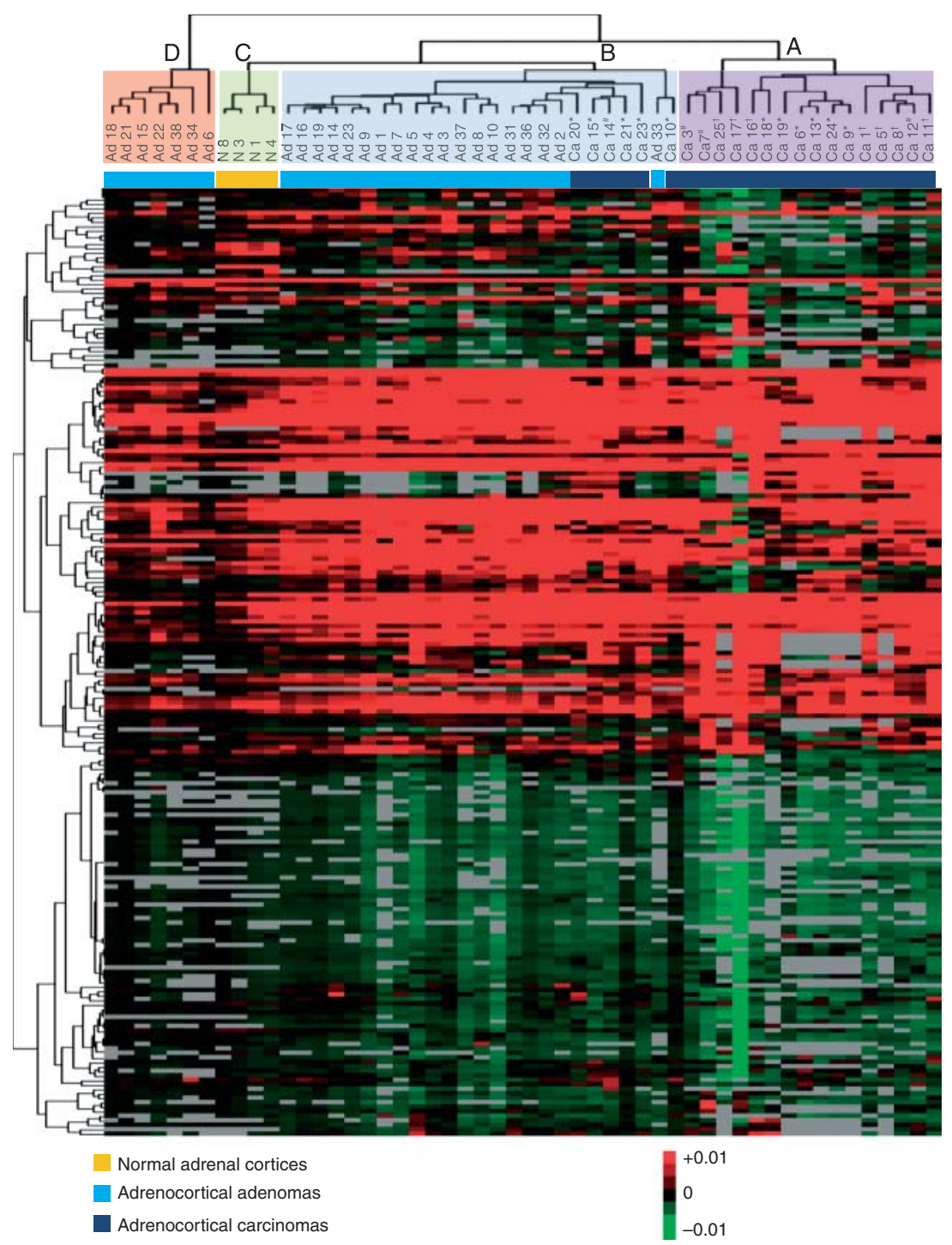

Figure 1 Unsupervised clustering analysis of microarray-based miRNA expression data for four normal adrenal cortices ( $\mathrm{N})$, 26 adenomas ( $\mathrm{Ad}$ ), and 22 carcinomas (Ca). Samples were clustered using the Spearman rank correlation and complete linkage. The four main clusters obtained (A-D) are indicated above the heatmap. Red and green colors indicate relatively high and low expression respectively. Missing values are indicated in gray. *Alive; ${ }^{\dagger}$ dead of disease; ${ }^{*}$ dead of unrelated or unknown causes.

on 213 miRNAs revealed four main clusters: cluster A consisted of the majority of carcinoma samples (16 of the 22 ACC; 72\%) and cluster B comprised 19 adenomas and the remaining six carcinomas. Five of the six ACC patients in cluster B are still alive at the end of follow-up and one died of unrelated causes with ACC after 65 months. All four normal adrenal cortices were grouped in cluster $\mathrm{C}$, and the remaining seven adenomas were included in cluster $\mathrm{D}$.

We also performed SAM analysis to identify the most significant deregulated miRNAs that could distinguish carcinomas from adenomas and adrenal cortices. The analysis identified 72 differentially expressed miRNAs with a false discovery rate (FDR) of $0 \%$ (Supplementary Table 3, see section on supplementary data given at the end of this article). Several of these miRNAs were also found to have significantly differential expression in the comparisons between carcinomas and adenomas or normal adrenal cortices (Supplementary Tables 4 and 5, see section on supplementary data given at the end of this article). To verify the significance of the results obtained by microarray analysis, we evaluated the expression levels of seven miRNAs (miR-483-3p, miR-483-5p, $m i R-210, m i R-21, m i R-1974, m i R-195$, and $m i R-497)$ by qRT-PCR in a series of 68 adrenocortical tumors 
(43 adenomas and 25 carcinomas) and ten normal adrenal cortices (Fig. 2). These miRNAs were selected among those with the highest score in the SAM analysis, or because of their involvement in adrenal cortical tumors or other tumor types. In concordance with the microarray results, the qRT-PCR analyses revealed significantly higher expression of $m i R-483$ 3p, $m i R-483-5 p, m i R-210$, and $m i R-21$, as well as lower expression of $m i R-1974, m i R-195$, and $m i R-497$ in carcinomas compared with adrenal cortices or adenomas (Fig. 2 and Supplementary Figure 2, see section on supplementary data given at the end of this article). Interestingly, two of these miRNAs, $m i R-483-3 p$ and $m i R-483-5 p$, were also significantly differential expressed between the carcinomas in cluster B and cluster A observed in unsupervised clustering (Supplementary Table 6 , see section on supplementary data given at the end of this article). The precursor of miR-497 is located at a distance of $\sim 200$ bases upstream of $m i R-195$ at chromosomal region $17 \mathrm{p} 13.1$, suggesting that $m i R-497$ and $m i R-195$ belong to the same miRNA cluster and are likely to be co-expressed. We found that the expression of miR-195 was strongly correlated with the miR-497 expression ( $\operatorname{corr}=0.9$, $P<0.00001$; Supplementary Figure 3, see section on supplementary data given at the end of this article).

\section{Effect of altered $m i R-483, m i R-195$, and $m i R-497$ expression on cell proliferation and apoptosis in $\mathrm{NCl}-\mathrm{H} 295 \mathrm{R}$ cells}

We further evaluated the functional consequences from dysregulation of four miRNAs in human NCI-H295R ACC cells. These miRNAs were chosen because of their associations with malignancy in adrenal cortical tumors. In Fig. 3A, inhibition of $m i R-483-3 p$ or $m i R-483-5 p$ expression resulted in significant reduction (20 and 30\% respectively), of cell proliferation compared with negative control cells (treated with anti-miR-negative control \#1). In addition, cells transfected with anti-miR-483-3p, but not with anti-miR-483-5p, showed a significant increase (approximately twofold) in apoptosis compared with cells transfected with negative control (Fig. 3A).

We also explored the functional consequences of $m i R-497$ and $m i R-195$ overexpression, which were found significantly downregulated in ACC compared with adenomas. In line with the effects observed for $m i R-483-3 p$, overexpression of $m i R-195$ or $m i R-497$ led to a significant decrease in cell growth (30 and $40 \%$ respectively), and a concomitant induction of cell death (40 and 30\% respectively), compared with negative control (Fig. 3B).
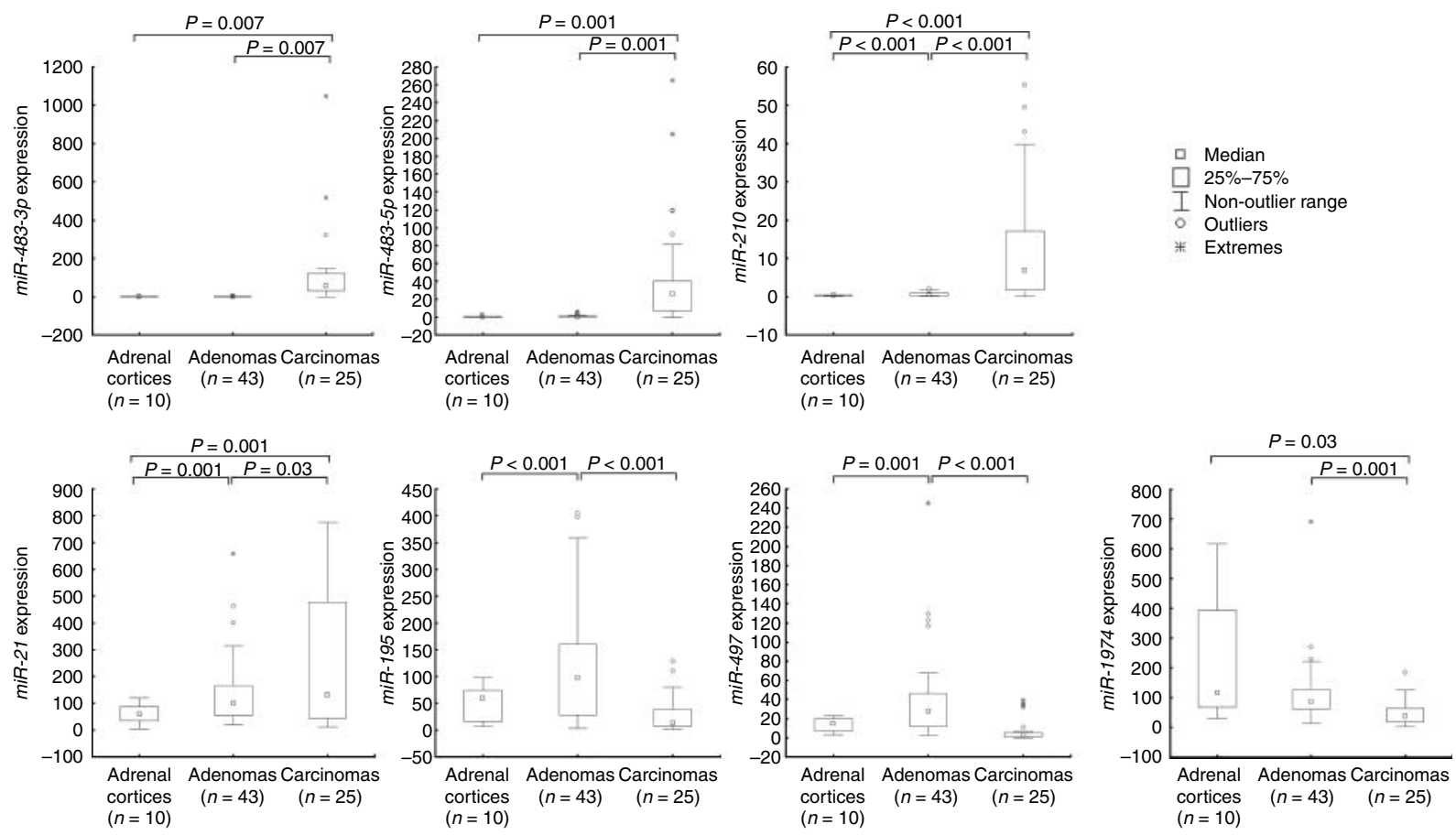

Figure 2 Relative expression levels of $m i R-483-3 p, m i R-483-5 p, m i R-210, m i R-21, m i R-195, m i R-497$, and $m i R-1974$ in the different sample groups. Box plots show miRNA expression levels determined by qRT-PCR in adrenocortical carcinomas, adenomas, and adrenal cortices. Statistical significances between the groups were determined with two-tailed unpaired $t$-test and $P<0.05$ were considered significant. 

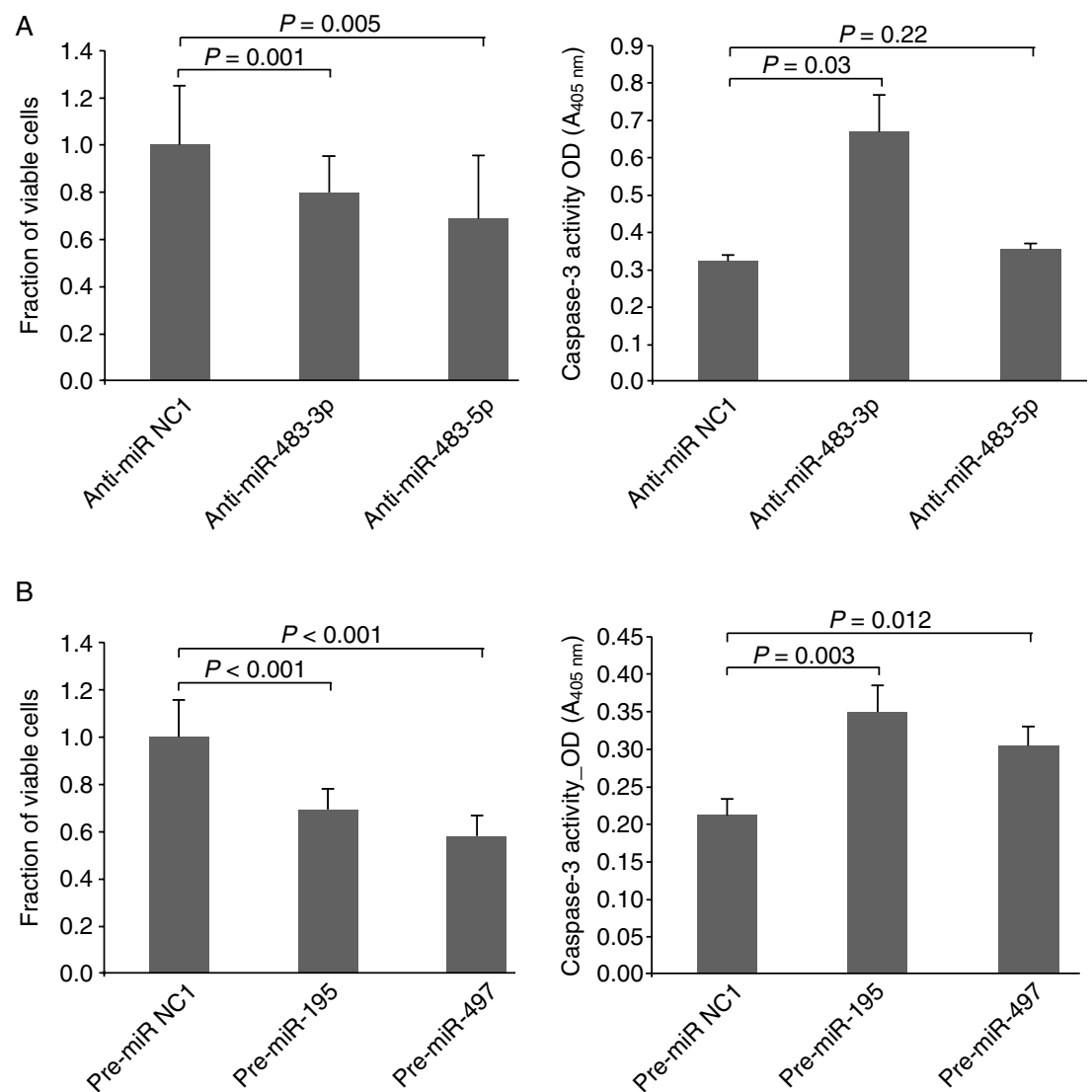

Figure 3 Effects of miR-483 inhibition and miR-497 or miR-195 overexpression on cell proliferation and apoptosis in NCl-H295R ACC cells. Cell viability was evaluated by WST-1 colorimetric assay and cell apoptosis by caspase-3 colorimetric assay upon (A) inhibition of $m i R-483-3 p$ and $m i R-483-5 p$ or $(\mathrm{B})$ overexpression of $m i R-195$ and $m i R-497$. Error bars represent S.D. of the mean from three independent experiments. Statistical significance between the two treatment conditions was evaluated by Student's paired $t$-test and $P<0.05$ was considered significant. NC1, negative control \#1.

\section{Relationship between miR-483-3p and PUMA expression in adrenocortical tumors}

Recent findings of the pro-apoptotic gene $B B C 3 / P U M A$ as a direct target of $m i R-483-3 p$ (Veronese et al. 2010), in combination with our observations of the pro-apoptotic and anti-proliferative effects of $m i R-483-3 p$ silencing, prompted us to investigate a possible connection between PUMA and $m i R-483-3 p$ expression in adrenocortical tumors. We measured the PUMA protein expression levels by western blot analysis in three normal adrenal cortical samples, 26 adenomas, and 22 carcinomas, and compared with the expression of $m i R-483-3 p$. In Fig. 4, high levels of PUMA expression were detected in almost all adenomas and adrenal cortices, but only in a small proportion of carcinomas. The PUMA protein expression was inversely correlated with the $m i R-483-3 p$ expression (corr $=-0.31, P=0.025$ ). Notably, those carcinomas expressing low levels of
miR-483-3p had a higher PUMA protein expression (e.g. Ca 20), and vice versa (e.g. Ca 6; Fig. 4).

\section{miRNAs associated with survival of ACC patients}

In an attempt to identify specific miRNAs associated with survival, we performed SAM survival analysis on the carcinoma cases. The analysis identified 11 miRNAs that could predict the disease outcome with a SAM survival score $>2.6$ (FDR: 0\%; Fig. 5A). Specifically high expression of $m i R-638, m i R-1246$, miR-1915, miR-1275, miR-503, miR-671-5p, miR1268, miR-762, miR-331-3p, miR-1202, and miR-572 were found associated with short survival (Fig. 5A). Although two of the carcinoma cases $(\mathrm{Ca} 23$ and $\mathrm{Ca}$ 24) had a shorter follow-up (25 and 20 months respectively), exclusion of these cases from the survival analyses did not affect the significance of our results. Using the miRNA set selected by SAM survival analysis, we performed a hierarchical 
A

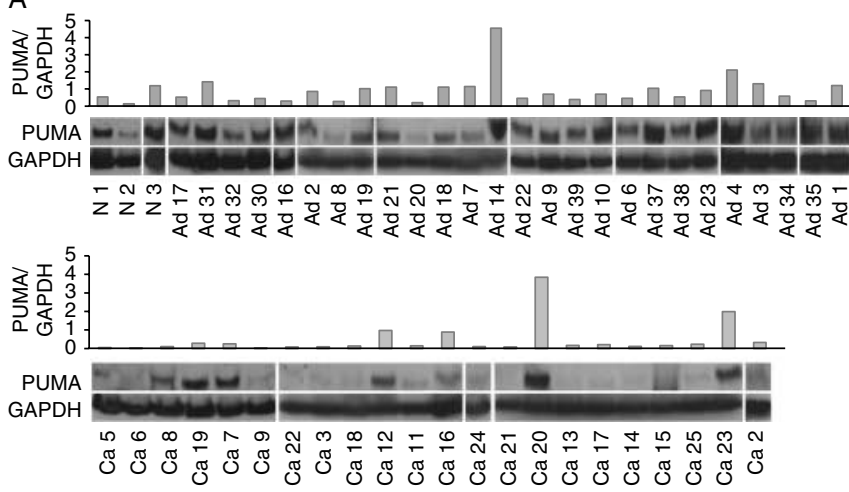

B

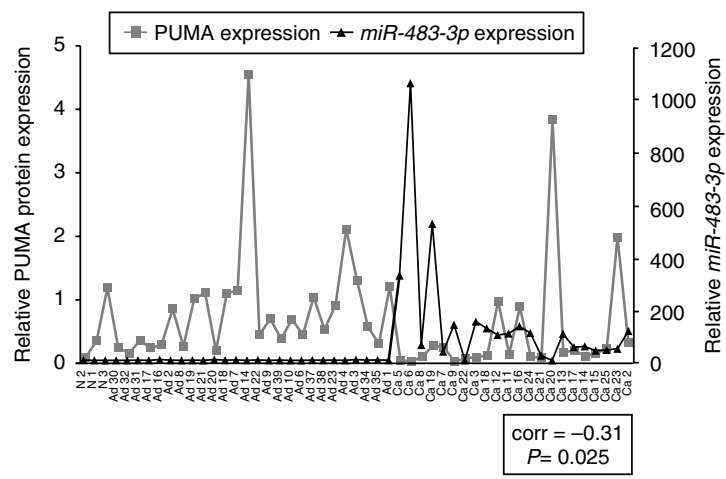

Figure 4 Correlation between expression of $m i R-483-3 p$ and its putative target PUMA. (A) Western blot analyses of PUMA expression and GAPDH used as reference in three adrenal cortical samples (N), 26 adenomas (Ad), and 22 carcinomas (Ca). The expression levels of PUMA shown in the diagram above were calculated by normalization against GAPDH protein levels. (B) Comparison between miR-483-3p expression and PUMA protein levels in individual samples. Correlation was assessed by Pearson correlation analysis.

clustering analysis and observed that the samples were classified into three clusters. As shown in Fig. 5A, the survival analysis revealed a significant difference between cluster 3 and the other two clusters $(P=0.03$, log-rank test). Furthermore, using KaplanMeier survival and log-rank analyses, we evaluated the association with survival for each individual miRNA detected by SAM. The analysis revealed six of these 11 miRNAs as significantly associated with survival (Supplementary Figure 4, see section on supplementary data given at the end of this article). High expression of $m i R-503(P<0.001$; log-rank test $), m i R$ $1202(P=0.009), m i R-1915 \quad(P=0.013), m i R-638$ $(P=0.018), m i R-572 \quad(P=0.024)$, and $m i R-1275$ $(P=0.035)$ were significantly associated with shorter overall survival (Supplementary Figure 4).

To validate the significance of these prognostic miRNAs, we evaluated the expression of six miRNAs in the cohort of 25 ACC by qRT-PCR. Using KaplanMeier survival curves and log-rank analysis, we confirmed the significant association of $m i R-503$ $(P=0.006), m i R-1202(P=0.005)$, and $m i R-1275$ $(P=0.042)$ with overall survival (Fig. 5B), which is in concordance with the array-based results. However, $m i R-572$, miR-1915, and miR-638 were not found statistically significant (data not shown).

\section{Discussion}

In this study, we identified a set of miRNAs that is differentially expressed between malignant and nonmalignant samples, and a small number of miRNAs associated with survival in ACC patients.

\section{miRNA deregulation in ACC}

Using a microarray approach, we identified distinct miRNA expression patterns between carcinoma and non-carcinoma samples. The consistency of the findings was supported by the validation of seven of the most significant differentially expressed miRNAs in an extended series of adrenocortical tumors by TaqMan qRT-PCR methodology. Taken together, the observations indicate the significant importance of these miRNAs in the pathogenesis of ACC.

We showed that $m i R-497$ expression is significantly reduced in ACC compared with adenomas. In concordance with our results, $m i R-497$ was reported underexpressed in childhood adrenocortical tumors (Doghman et al. 2010). Decreased expression of $m i R-497$ has also been observed in peritoneal carcinoma (Flavin et al. 2009) and male breast cancer (Lehmann et al. 2010). Downregulation of miR-195 was recently reported in adult ACC (Soon et al. 2009b), which is consistent with our results. The precursors of $m i R-497$ and $m i R-195$ are likely generated from the same miRNA cluster because of their close proximity in genomic location. A strong positive correlation between miR-497 and miR-195 expressions also indicates that these two miRNAs were co-expressed. The co-expression of the miR-497-195 cluster suggests that these miRNAs could be co-regulated by common transcriptional factor(s) and they may have some common functions. Although the factor(s) regulating the transcription of this miRNA cluster are yet unknown, a common deletion within this chromosomal region (17p13) has been reported in ACC (Kjellman et al. 1996, Soon et al. 2008), but not in benign adrenocortical conditions (Almeida et al. 2011). This may, at least in 
A

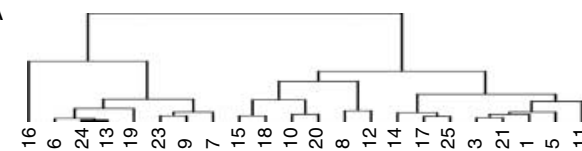
రీ రీ రూ

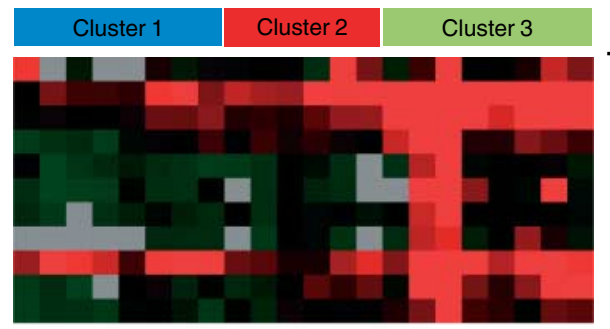

\begin{tabular}{lc} 
miRNA & $\begin{array}{c}\text { SAM survival } \\
\text { score }\end{array}$ \\
\hline miR-503 & 3.08 \\
miR-638 & 3.85 \\
miR-1915 & 3.43 \\
miR-762 & 2.96 \\
miR-1275 & 3.18 \\
miR-1246 & 3.61 \\
miR-1268 & 2.97 \\
miR-671-5p & 3.05 \\
miR-331-3p & 2.86 \\
miR-1202 & 2.85 \\
miR-572 & 2.61
\end{tabular}
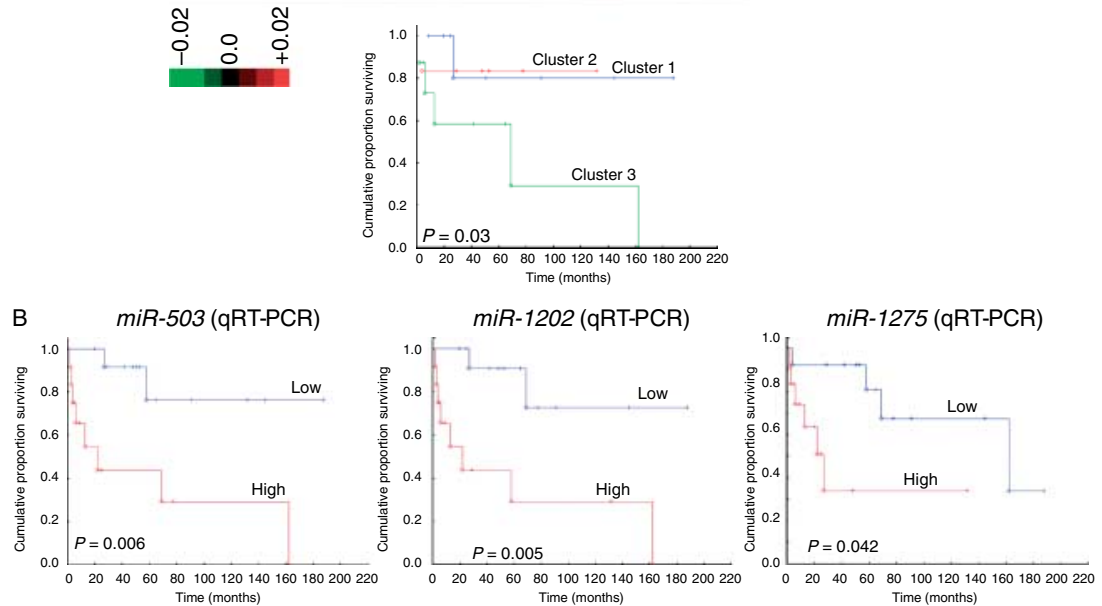

Figure 5 miRNAs associated with survival of carcinoma patients. (A) Clustering analysis of 11 miRNAs identified by SAM survival analysis of microarray data, and subsequent Kaplan-Meier analysis for cases in cluster 1-3. (B) Kaplan-Meier curves for miR-503, miR-1202, and miR-1275 based on qRT-PCR results. Differences in survival were calculated using log-rank test.

part, explain the reduced expression of the $m i R-497-195$ cluster in ACC.

Despite the expression association, functional roles of miRNAs in ACC cells remain uncharacterized. In this study, we demonstrate the functional role of deregulated miRNAs in ACC cells using experimental cell culture systems. Overexpression of miR-195 or miR-497 in the NCI-H295R human ACC cell line could significantly reduce cell proliferation in combination with a pro-apoptotic effect. Consistent with our findings, miR-497 was previously shown to promote neural death by negatively regulating expression of anti-apoptotic proteins, bcl-2 and bcl-w (Yin et al. 2010). Moreover, overexpression of miR-195 could induce cell cycle arrest in hepatocellular carcinoma cells (Xu et al. 2009) and promote cell apoptosis in human colorectal cancer cells (Liu et al. 2010). Taken together, these findings revealed the potential tumor suppressive role and pro-apoptotic activity of this miRNA cluster in ACC and other cell types. Further investigation is certainly warranted to identify their potential targets and elucidate their mechanisms of action in ACC development.

We also demonstrated that $m i R-483-3 p$ and $m i R-483-5 p$ expression levels were significantly higher in carcinomas compared with the benign or normal counterparts. Concordantly, overexpression of $m i R-483-3 p$ and $m i R-483-5 p$ were recently reported in childhood adrenocortical tumors (Doghman et al. 2010) and adult ACC (Patterson et al. 2011) respectively. However, Soon et al. (2009b) observed a non-significant trend for $m i R-483$ overexpression in adult ACC versus adenomas, where the lack of statistical significance could result from the relatively limited sample size. $m i R-483-3 p$ and $m i R-483-5 p$ are derived from different arms $\left(3^{\prime}\right.$ and $5^{\prime}$ arms respectively), of the same miRNA precursor. Although both $m i R-483-3 p$ and $m i R-483-5 p$ were significantly upregulated in carcinomas, we noted that the $3^{\prime}$-strand was much more abundant than the $5^{\prime}$-strand.

Overexpression of $m i R-483-3 p$ may be a common alteration of tumor cells in several different tumor 
types. In addition to ACC, overexpression of $m i R$ 483-3p has also been demonstrated in Wilms' tumors, and in colon, breast, and liver cancers (Veronese et al. 2010). Importantly, Veronese et al. (2010) recently demonstrated that silencing of $m i R-483-3 p$ could suppress cell proliferation and induce apoptosis in the hepatocarcinoma cell line HepG2, as well as inhibit tumorigenicity in vivo. In line with their findings, we also observed a significant decrease in cell proliferation and increase in apoptosis by suppressing $m i R-483-3 p$ expression in the human ACC cell line NCI-H295R. PUMA was identified as a target of miR-483-3p (Veronese et al. 2010). We also observed a significant inverse correlation between PUMA protein expression and $m i R-483-3 p$ expression levels in ACC. The data support the expected inverse relationship between miRNA and target gene expressions.

$m i R-483-5 p$ overexpression has been reported in tumors of the adrenal gland, such as ACC (Patterson et al. 2011) and pheochromocytoma (Meyer-Rochow et al. 2010). Although Ma et al. (2011) recently demonstrated that miR-483-5p directly targets Socs 3 in the mouse hepatoma Hepa 1-6 cells, its function remains uncharacterized. In this study, we show that $m i R-483-5 p$ also promotes cell proliferation but has no effect on apoptosis in NCI-H295R ACC cells. The differential effect on apoptosis by $m i R-483-3 p$ and $m i R-483-5 p$ may be related to the pro-apoptotic PUMA. While PUMA is a target of $m i R-483-3 p$, computational prediction and expression correlation between $m i R-483-5 p$ and PUMA expression (data not shown) suggest that PUMA is not a target of $m i R-483-5 p$. Taken together, $m i R-483$ is involved in various cancer types and $m i R-483-3 p$ plays an important role in anti-apoptotic protection.

In addition, we also observed a significantly increased expression of $m i R-21$ and $m i R-210$ in ACC compared with adenomas and adrenal cortices. Overexpression of $m i R-21$ has been reported in several tumor types, such as glioblastoma (Chan et al. 2005), breast cancer (Iorio et al. 2005, Yan et al. 2008), chronic lymphocytic leukemia (Fulci et al. 2007), and cervical cancer (Lui et al. 2007). Several studies also showed that miR-21 knockdown could impair cell growth, induce apoptosis and interfere with cell migration and invasion of cancer cells (Chan et al. 2005, Si et al. 2007, Asangani et al. 2008, Zhu et al. 2008). Although overexpression of $m i R-21$ has not been reported in previous miRNA profiling studies of ACC (Soon et al. 2009b, Tombol et al. 2009, Doghman et al. 2010, Patterson et al. 2011), its upregulation has been shown to promote cell proliferation in human NCI-H295R ACC cells (Romero et al. 2008). These lines of evidence suggest that $m i R-21$ plays a common oncogenic role in several tumor types, including ACC.

Overexpression of miR-210 appears to be a common feature in many tumor types (Camps et al. 2008, Huang et al. 2009, Zhang et al. 2009, Greither et al. 2010) and several reports have shown that its expression is regulated by hypoxia-inducible factor $1 \alpha$ (HIF $1 \alpha)$. Hypoxia is frequently found in tumors and is associated with radiation-resistance and chemotherapyresistance, increased metastatic potential and poor outcome (Pouyssegur et al. 2006, Lee et al. 2007). However, virtually no studies have so far been reported that evaluate the role of hypoxia in the pathogenesis of ACC. Further investigations are warranted to determine the involvement of hypoxia and the role of $m i R-210$ in ACC development or progression.

\section{miRNAs associated with survival in ACC}

Recently, Soon et al. (2009b) identified two miRNAs (i.e. $m i R-483-5 p$ and $m i R-195$ ) associated with survival in ACC using Exiqon miRCURY LNA microarray, however these miRNAs were not significantly associated with survival in our cohort using both Agilent microarray and qRT-PCR methods (data not shown). The discrepancy could be due to differences in sample characteristics, platforms, and data analysis methods.

In this study, we demonstrate that ACC can be divided into different subgroups with different clinical outcomes based on their miRNA expression profiles. Cluster 3 is associated with poorer outcome, in which most patients were died of the disease. The overall survival is apparently better in the other two clusters in which most patients are still alive. However, no distinct histologic features were found between the two subgroups (data not shown). Survival analysis revealed that high expression of $m i R-503, m i R-1202$, and $m i R-1275$ are significantly associated with poor survival of ACC patients. Notably, increased expression of $m i R-503$ has been observed in various human tumors, including parathyroid carcinoma (Corbetta et al. 2010), retinoblastoma (Zhao et al. 2009), and ACC (Soon et al. 2009b, Tombol et al. 2009). However, to our knowledge, the association between $m i R-503$ expression and survival has not been reported in any cancer type. Functionally, miR-503 has been shown to directly target cell cycle regulators, which leads to induction of G1 cell cycle arrest in various cancer cell lines and promotion of cell differentiation in monocytes and myoblasts (Forrest et al. 2010, Sarkar et al. 2010). Although miR-503 is important for promoting cell cycle arrest and differentiation, its role in tumor progression has yet to be 
elucidated. The other two miRNAs demonstrating significant association with survival, miR-1202 and $m i R-1275$, have not been described in any cancer types. Nothing is known about their expression levels and function.

In conclusion, our findings show deregulation of a subset of miRNAs in ACC together with a potential role of $m i R-483, m i R-195$, and $m i R-497$ in the pathogenesis of this neoplasm. Our study also reveals that high expression of $m i R-503, m i R-1202$, and $m i R-1275$ are associated with poor survival of ACC patients, suggesting their potential prognostic value in ACC.

\section{Supplementary data}

This is linked to the online version of the paper at http://dx. doi.org/10.1530/ERC-11-0082.

\section{Declaration of interest}

The authors declare that there is no conflict of interest that could be perceived as prejudicing the impartiality of the research reported.

\section{Funding}

This work was supported by the Swedish Research Council (523-2009-3517 and 521-2010-3518); the Ảke Olsson's Foundation for Hematological Research; the Cancer Research Funds of Radiumhemmet; the Axel and Signe Lagerman's Donation Foundation; the Swedish Cancer Society; Göran Gustafsson Foundation for Research on Natural Sciences and Medicine; Karolinska Institutet and Stockholm County Council.

\section{Author contribution statement}

D M Ö, S C, C L, and W-O L conceived and designed the experiments; D M Ö, S C, D V-F, P A, and H X performed the experiments; D M Ö, S C, D V-F, P A, H X, and W-O L analyzed the data; $\mathrm{M} \mathrm{B}, \mathrm{C} \mathrm{L}, \mathrm{A} \mathrm{H}$, and $\mathrm{J} \mathrm{Z}$ contributed to clinical and histopathological information of the cases; D M Ö, S C, C L, and W-O L wrote the manuscript; All authors have read and approved the final version of the manuscript.

\section{Acknowledgements}

We thank Ms Lisa Ånfalk for excellent assistance in collection of the tumor samples and the members of the Medical Genetics group for their helps and suggestions.

\section{References}

Almeida MQ, Harran M, Bimpaki EI, Hsiao HP, Horvath A, Cheadle C, Watkins T, Nesterova M \& Stratakis CA 2011
Integrated genomic analysis of nodular tissue in macronodular adrenocortical hyperplasia: progression of tumorigenesis in a disorder associated with multiple benign lesions. Journal of Clinical Endocrinology and Metabolism 96 E728-E738. (doi:10.1210/jc.2010-2420)

Asangani IA, Rasheed SA, Nikolova DA, Leupold JH, Colburn NH, Post S \& Allgayer H 2008 MicroRNA-21 (miR-21) post-transcriptionally downregulates tumor suppressor Pdcd4 and stimulates invasion, intravasation and metastasis in colorectal cancer. Oncogene 27 2128-2136. (doi:10.1038/sj.onc.1210856)

Bertherat J, Groussin L \& Bertagna X 2006 Mechanisms of disease: adrenocortical tumors - molecular advances and clinical perspectives. Nature Clinical Practice. Endocrinology \& Metabolism 2 632-641. (doi:10.1038/ ncpendmet0321)

Bimpaki EI, Iliopoulos D, Moraitis A \& Stratakis CA 2010 MicroRNA signature in massive macronodular adrenocortical disease and implications for adrenocortical tumourigenesis. Clinical Endocrinology 72 744-751. (doi:10.1111/j.1365-2265.2009.03725.x)

Camps C, Buffa FM, Colella S, Moore J, Sotiriou C, Sheldon H, Harris AL, Gleadle JM \& Ragoussis J 2008 hsa-miR-210 Is induced by hypoxia and is an independent prognostic factor in breast cancer. Clinical Cancer Research 14 1340-1348. (doi:10.1158/1078-0432.CCR07-1755)

Caramuta S, Egyhazi S, Rodolfo M, Witten D, Hansson J, Larsson C \& Lui WO 2010 MicroRNA expression profiles associated with mutational status and survival in malignant melanoma. Journal of Investigative Dermatology 130 2062-2070. (doi:10.1038/jid.2010.63)

Chan JA, Krichevsky AM \& Kosik KS 2005 MicroRNA-21 is an antiapoptotic factor in human glioblastoma cells. Cancer Research 65 6029-6033. (doi:10.1158/00085472.CAN-05-0137)

Corbetta S, Vaira V, Guarnieri V, Scillitani A, EllerVainicher C, Ferrero S, Vicentini L, Chiodini I, Bisceglia M, Beck-Peccoz P et al. 2010 Differential expression of microRNAs in human parathyroid carcinomas compared with normal parathyroid tissue. Endocrine-Related Cancer 17 135-146. (doi:10.1677/ERC-09-0134)

DeLellis RA, Lloyd RV, Heitz PU \& Eng C 2004 Pathology and genetics of tumours of endocrine organs. In World Health Organization Classification of Tumours. Lyon, France: IARC Press.

Doghman M, El Wakil A, Cardinaud B, Thomas E, Wang J, Zhao W, Peralta-Del Valle MH, Figueiredo BC, Zambetti GP \& Lalli E 2010 Regulation of insulin-like growth factor-mammalian target of rapamycin signaling by microRNA in childhood adrenocortical tumors. Cancer Research 70 4666-4675. (doi:10.1158/0008-5472.CAN09-3970)

Ferracin M, Veronese A \& Negrini M 2010 Micromarkers: miRNAs in cancer diagnosis and prognosis. Expert Review of Molecular Diagnostics 10 297-308. (doi:10. 1586/erm.10.11) 
Flavin RJ, Smyth PC, Laios A, O’Toole SA, Barrett C, Finn SP, Russell S, Ring M, Denning KM, Li J et al. 2009 Potentially important microRNA cluster on chromosome $17 \mathrm{p} 13.1$ in primary peritoneal carcinoma. Modern Pathology 22 197-205. (doi:10.1038/modpathol.2008.135)

Forrest AR, Kanamori-Katayama M, Tomaru Y, Lassmann T, Ninomiya N, Takahashi Y, de Hoon MJ, Kubosaki A, Kaiho A, Suzuki M et al. 2010 Induction of microRNAs, mir-155, mir-222, mir-424 and mir-503, promotes monocytic differentiation through combinatorial regulation. Leukemia 24 460-466. (doi:10.1038/leu. 2009.246)

de Fraipont F, El Atifi M, Cherradi N, Le Moigne G, Defaye G, Houlgatte R, Bertherat J, Bertagna X, Plouin PF, Baudin E et al. 2005 Gene expression profiling of human adrenocortical tumors using complementary deoxyribonucleic acid microarrays identifies several candidate genes as markers of malignancy. Journal of Clinical Endocrinology and Metabolism 90 1819-1829. (doi:10. 1210/jc.2004-1075)

Fulci V, Chiaretti S, Goldoni M, Azzalin G, Carucci N, Tavolaro S, Castellano L, Magrelli A, Citarella F, Messina M et al. 2007 Quantitative technologies establish a novel microRNA profile of chronic lymphocytic leukemia. Blood 109 4944-4951. (doi:10.1182/blood2006-12-062398)

Giordano TJ, Thomas DG, Kuick R, Lizyness M, Misek DE, Smith AL, Sanders D, Aljundi RT, Gauger PG, Thompson NW et al. 2003 Distinct transcriptional profiles of adrenocortical tumors uncovered by DNA microarray analysis. American Journal of Pathology 162 521-531. (doi:10.1016/S0002-9440(10)63846-1)

Giordano TJ, Kuick R, Else T, Gauger PG, Vinco M, Bauersfeld J, Sanders D, Thomas DG, Doherty G \& Hammer G 2009 Molecular classification and prognostication of adrenocortical tumors by transcriptome profiling. Clinical Cancer Research 15 668-676. (doi:10. 1158/1078-0432.CCR-08-1067)

Greither T, Grochola LF, Udelnow A, Lautenschlager C, Wurl P \& Taubert H 2010 Elevated expression of microRNAs 155, 203, 210 and 222 in pancreatic tumors is associated with poorer survival. International Journal of Cancer 126 73-80. (doi:10.1002/ijc.24687)

de Hoon MJ, Imoto S, Nolan J \& Miyano S 2004 Open source clustering software. Bioinformatics 20 1453-1454. (doi:10.1093/bioinformatics/bth078)

Huang X, Ding L, Bennewith KL, Tong RT, Welford SM, Ang KK, Story M, Le QT \& Giaccia AJ 2009 Hypoxiainducible mir-210 regulates normoxic gene expression involved in tumor initiation. Molecular Cell 35 856-867. (doi:10.1016/j.molcel.2009.09.006)

Iliopoulos D, Bimpaki EI, Nesterova M \& Stratakis CA 2009 MicroRNA signature of primary pigmented nodular adrenocortical disease: clinical correlations and regulation of Wnt signaling. Cancer Research 69 3278-3282. (doi:10.1158/0008-5472.CAN-09-0155)
Iorio MV \& Croce CM 2009 MicroRNAs in cancer: small molecules with a huge impact. Journal of Clinical Oncology 27 5848-5856. (doi:10.1200/JCO.2009.24. 0317)

Iorio MV, Ferracin M, Liu CG, Veronese A, Spizzo R, Sabbioni S, Magri E, Pedriali M, Fabbri M, Campiglio M et al. 2005 MicroRNA gene expression deregulation in human breast cancer. Cancer Research 65 7065-7070. (doi:10.1158/0008-5472.CAN-05-1783)

Kjellman M, Kallioniemi OP, Karhu R, Hoog A, Farnebo LO, Auer G, Larsson C \& Backdahl M 1996 Genetic aberrations in adrenocortical tumors detected using comparative genomic hybridization correlate with tumor size and malignancy. Cancer Research 56 4219-4223.

Laurell C, Velazquez-Fernandez D, Lindsten K, Juhlin C, Enberg U, Geli J, Hoog A, Kjellman M, Lundeberg J, Hamberger B et al. 2009 Transcriptional profiling enables molecular classification of adrenocortical tumours. European Journal of Endocrinology 161 141-152. (doi:10.1530/EJE-09-0068)

Lee KA, Roth RA \& LaPres JJ 2007 Hypoxia, drug therapy and toxicity. Pharmacology \& Therapeutics 113 229-246. (doi:10.1016/j.pharmthera.2006.08.001)

Lehmann U, Streichert T, Otto B, Albat C, Hasemeier B, Christgen H, Schipper E, Hille U, Kreipe HH \& Langer F 2010 Identification of differentially expressed microRNAs in human male breast cancer. BMC Cancer 10109. (doi:10.1186/1471-2407-10-109)

Liu L, Chen L, Xu Y, Li R \& Du X 2010 microRNA-195 promotes apoptosis and suppresses tumorigenicity of human colorectal cancer cells. Biochemical and Biophysical Research Communications 400 236-240. (doi:10.1016/j.bbrc.2010.08.046)

Lui WO, Pourmand N, Patterson BK \& Fire A 2007 Patterns of known and novel small RNAs in human cervical cancer. Cancer Research 67 6031-6043. (doi:10.1158/ 0008-5472.CAN-06-0561)

Ma N, Wang X, Qiao Y, Li F, Hui Y, Zou C, Jin J, Lv G, Peng Y, Wang L et al. 2011 Coexpression of an intronic microRNA and its host gene reveals a potential role for miR-483-5p as an IGF2 partner. Molecular and Cellular Endocrinology 333 96-101. (doi:10.1016/j.mce.2010.11. 027)

Meyer-Rochow GY, Jackson NE, Conaglen JV, Whittle DE, Kunnimalaiyaan M, Chen H, Westin G, Sandgren J, Stalberg P, Khanafshar E et al. 2010 MicroRNA profiling of benign and malignant pheochromocytomas identifies novel diagnostic and therapeutic targets. EndocrineRelated Cancer 17 835-846. (doi:10.1677/ERC-10-0142)

Patterson EE, Holloway AK, Weng J, Fojo T \& Kebebew E 2011 MicroRNA profiling of adrenocortical tumors reveals miR-483 as a marker of malignancy. Cancer 117 1630-1639. (doi:10.1002/cncr.25724)

Pouyssegur J, Dayan F \& Mazure NM 2006 Hypoxia signalling in cancer and approaches to enforce tumour regression. Nature 441 437-443. (doi:10.1038/ nature04871) 
de Reynies A, Assie G, Rickman DS, Tissier F, Groussin L, Rene-Corail F, Dousset B, Bertagna X, Clauser E \& Bertherat J 2009 Gene expression profiling reveals a new classification of adrenocortical tumors and identifies molecular predictors of malignancy and survival. Journal of Clinical Oncology 27 1108-1115. (doi:10. 1200/JCO.2008.18.5678)

Romero DG, Plonczynski MW, Carvajal CA, Gomez-Sanchez EP \& Gomez-Sanchez CE 2008 Microribonucleic acid-21 increases aldosterone secretion and proliferation in H295R human adrenocortical cells. Endocrinology 149 2477-2483. (doi:10.1210/en.2007-1686)

Sarkar S, Dey BK \& Dutta A 2010 MiR-322/424 and -503 are induced during muscle differentiation and promote cell cycle quiescence and differentiation by down-regulation of Cdc25A. Molecular Biology of the Cell 21 2138-2149. (doi:10.1091/mbc.E10-01-0062)

Si ML, Zhu S, Wu H, Lu Z, Wu F \& Mo YY 2007 miR-21-mediated tumor growth. Oncogene 26 2799-2803. (doi:10.1038/sj.onc.1210083)

Soon PS, Libe R, Benn DE, Gill A, Shaw J, Sywak MS, Groussin L, Bertagna X, Gicquel C, Bertherat J et al. 2008 Loss of heterozygosity of $17 \mathrm{p} 13$, with possible involvement of ACADVL and ALOX15B, in the pathogenesis of adrenocortical tumors. Annals of Surgery 247 157-164. (doi:10.1097/SLA.0b013e318153ff55)

Soon PS, Gill AJ, Benn DE, Clarkson A, Robinson BG, McDonald KL \& Sidhu SB $2009 a$ Microarray gene expression and immunohistochemistry analyses of adrenocortical tumors identify IGF2 and Ki-67 as useful in differentiating carcinomas from adenomas. EndocrineRelated Cancer 16 573-583. (doi:10.1677/ERC-08-0237)

Soon PS, Tacon LJ, Gill AJ, Bambach CP, Sywak MS, Campbell PR, Yeh MW, Wong SG, Clifton-Bligh RJ, Robinson BG et al. $2009 b$ miR-195 and miR-483-5p identified as predictors of poor prognosis in adrenocortical cancer. Clinical Cancer Research 15 7684-7692. (doi:10.1158/1078-0432.CCR-09-1587)

Tombol Z, Szabo PM, Molnar V, Wiener Z, Tolgyesi G, Horanyi J, Riesz P, Reismann P, Patocs A, Liko I et al. 2009 Integrative molecular bioinformatics study of human adrenocortical tumors: microRNA, tissue-specific target prediction, and pathway analysis. EndocrineRelated Cancer 16 895-906. (doi:10.1677/ERC-09-0096)

Velazquez-Fernandez D, Laurell C, Geli J, Hoog A, Odeberg J, Kjellman M, Lundeberg J, Hamberger B, Nilsson P \&
Backdahl M 2005 Expression profiling of adrenocortical neoplasms suggests a molecular signature of malignancy. Surgery 138 1087-1094. (doi:10.1016/j.surg.2005.09. 031)

Veronese A, Lupini L, Consiglio J, Visone R, Ferracin M, Fornari F, Zanesi N, Alder H, D'Elia G, Gramantieri L et al. 2010 Oncogenic role of miR-483-3p at the IGF2/483 locus. Cancer Research 70 3140-3149. (doi:10.1158/ 0008-5472.CAN-09-4456)

Xu T, Zhu Y, Xiong Y, Ge YY, Yun JP \& Zhuang SM 2009 MicroRNA-195 suppresses tumorigenicity and regulates G1/S transition of human hepatocellular carcinoma cells. Hepatology 50 113-121. (doi:10.1002/ hep.22919)

Yan LX, Huang XF, Shao Q, Huang MY, Deng L, Wu QL, Zeng YX \& Shao JY 2008 MicroRNA miR-21 overexpression in human breast cancer is associated with advanced clinical stage, lymph node metastasis and patient poor prognosis. RNA 14 2348-2360. (doi:10.1261/ rna.1034808)

Yin KJ, Deng Z, Huang H, Hamblin M, Xie C, Zhang J \& Chen YE 2010 miR-497 regulates neuronal death in mouse brain after transient focal cerebral ischemia. Neurobiological Disorders 38 17-26. (doi:10.1016/j.nbd. 2009.12.021)

Zhang Z, Sun H, Dai H, Walsh RM, Imakura M, Schelter J, Burchard J, Dai X, Chang AN, Diaz RL et al. 2009 MicroRNA miR-210 modulates cellular response to hypoxia through the MYC antagonist MNT. Cell Cycle $\mathbf{8}$ 2756-2768. (doi:10.4161/cc.8.17.9387)

Zhao JJ, Yang J, Lin J, Yao N, Zhu Y, Zheng J, Xu J, Cheng JQ, Lin JY \& Ma X 2009 Identification of miRNAs associated with tumorigenesis of retinoblastoma by miRNA microarray analysis. Child's Nervous System 25 13-20. (doi:10.1007/s00381-008-0701-x)

Zhu S, Wu H, Wu F, Nie D, Sheng S \& Mo YY 2008 MicroRNA-21 targets tumor suppressor genes in invasion and metastasis. Cell Research 18 350-359. (doi:10.1038/ cr.2008.24)

Received in final form 22 July 2011

Accepted 22 August 2011

Made available online as an Accepted Preprint 22 August 2011 